... as dental students we take several years

to just begin to feel confident at restoring a

patient's mouth and then assume we can

adopt communication skills with hardly

any practice at all.

\title{
Make me an offer
}

My first serious attempt at negotiation was on holiday in Singapore. I had been advised that if I wanted to buy anything I had to haggle and drive the price down. With some trepidation I looked at the pearl earrings I had chosen as a present for my wife and offered two thirds the asking price. To my amazement the man behind the counter accepted immediately, and I walked away feeling I had really driven a hard bargain (and to be honest feeling rather smug). Later I came to realise that the fact he had accepted so readily meant I had pitched my offer far too high.

Negotiation skills often do not come naturally to people raised in the United Kingdom, although some people revel in it - usually to the envy of their peers. In my own case I felt that somehow it was not quite the done thing, as I assumed that the person asking the price was asking a fair price. After all, in my own case that was the way I worked when setting a price for something I was selling. As a dentist I was even less likely to argue over price when either buying or selling. After all, I was a professional.

Yet negotiation is exactly what dentists are going to have to learn if they are to survive in NHS general dental practice after October 2005, unless the goalposts move yet again. The new NHS contract is preparing to unleash a world of localised negotiations for all GDPs who wish to continue to offer NHS dentistry. At the moment it appears many of the PCTs are as uncertain what the future will hold as we are, but that will not last long. They will learn what they can expect or demand from any practitioners willing to deal with them, and they will learn it faster than we will.

Yet negotiation is not really all that hard. The basics are simple. The problem is that negotiation skills, like communication skills and clinical skills, require practice. I continue to be amazed at how as dental students we take several years to just begin to feel confident at restoring a patient's mouth and then assume we can adopt communication skills with hardly any practice at all. This means that any practitioner approaching a PCT to discuss (negotiate) a contract without suitable practice is rather like approaching a patient to perform a complex MOD having picked up an air rotor for the first time the day before. Perhaps a more apt description is that it would be more like restoring a tooth having simply read an appropriate text book. I know I would not be happy if I was the patient in that situation.

Luckily there are many opportunities to practice negotiation. We can practice anywhere, negotiating in the High Street (although you try persuading a sales assistant in Marks and Spencer that you want 20\% knocked off the price of a pair of socks), at work, at home with our family or with our friends. In fact we often do negotiate in social situations but we just do not realise it. But once money comes into the equation then we seem to forget we know the principles and lose all our confidence.

Like so many other things the secret is simple. To negotiate successfully, find out what the other person wants, and then try to balance a deal by exchanging what you want for what they want. In many cases this can be achieved without too much trouble, and is referred to as a win/win situation. Even if it cannot, by being prepared to listen and make an appropriate offer or concession we can usually achieve a mutuallyacceptable solution.

The problem comes when you do not prepare carefully enough and find you have in fact lost more than you need (as I did with the earrings). Then your negotiation will leave you in a lose/win situation (they win and you lose) and that creates bad feeling and a desire to get even later. Not a good basis for an ongoing relationship, as working with a PCT should be. And if that happens then the outcome is likely to be a constant feeling of frustration and a constant belief that you are being disadvantaged by the all-powerful system.

$\mathrm{Oh}$ - I think I just described the current perception of the GDS.

Mike Grace, Editor

m.grace@bda.org

doi: 10.1038/sj.bdj.4811894 